OPEN ACCESS

Edited by:

Valentí Rull,

Instituto de Ciencias de la Tierra Jaume Almera (CSIC), Spain

Reviewed by:

Mariusz Lamentowicz, Adam Mickiewicz University in

Poznan, Poland

Bas Van Geel,

University of Amsterdam, Netherlands

*Correspondence:

Miguel Montoro Girona

miguel.montoro.girona@slu.se

${ }^{\dagger}$ First authors.

Specialty section:

This article was submitted to

Paleoecology,

a section of the journal

Frontiers in Ecology and Evolution

Received: 27 October 2017

Accepted: 09 January 2018

Published: 26 January 2018

Citation:

Montoro Girona M, Navarro $L$ and Morin H (2018) A Secret Hidden in the

Sediments: Lepidoptera Scales.

Front. Ecol. Evol. 6:2

doi: $10.3389 /$ fevo.2018.00002

\section{A Secret Hidden in the Sediments: Lepidoptera Scales}

\author{
Miguel Montoro Girona ${ }^{1,2 \star t}$, Lionel Navarro ${ }^{1 \dagger}$ and Hubert Morin ${ }^{1}$ \\ 'Department of Fundamental Sciences, Université du Québec à Chicoutimi, Saguenay, Québec, QC, Canada, ${ }^{2}$ Department \\ of Wildlife, Fish, and Environmental Studies, Swedish University of Agricultural Sciences (SLU), Umeå, Sweden
}

Natural disturbance is one of the major topics in forest ecology. However, most paleoecological studies have only considered the influence of wildfire as an agent of disturbance, with fire history based primarily on the use of charcoal as a proxy for fire events. The frequency and intensity of insect outbreaks and their effect on the forest landscape have been neglected due to the absence of an effective proxy tool. Finding indicators able to provide insight into the impacts of past insect outbreaks is therefore essential. Fossil moth (Lepidoptera) scales offer a new approach for interpreting past insect-related disturbances and assessing the interactions between climate, fire and insect outbreaks. Paleoindicators must respond to three main criteria: (1) be in high abundance, (2) allow for easy identification and (3) remain well-preserved in sediment records. We demonstrate that wing scales are abundant in the boreal forest during insect outbreak periods. We also show that due to their chitin composition, these scales remain well-preserved throughout a 10,000-year sediment record. Furthermore, they are relatively easy to identify after being recovered from lake sediments. Therefore, we introduce the needs, potential and applications of this paleoindicator in forest ecology, and the main directions for the future research. This new approach offers an important scientific advance in ecology through a much improved, higher resolution reconstruction of an important natural disturbance: insect outbreaks.

Keywords: climate change, forest ecology, Holocene, insect outbreaks, natural disturbance, paleoecology, sustainable forest management

Forests are complex and dynamic systems, with numerous ecological factors and processes interacting at multiples scales to create landscapes inherited from thousands years of disturbance (Messier et al., 2013; Montoro Girona et al., 2017). Until recently, most paleoecological studies, especially within the boreal biome, have only assessed the influence of wildfire as a disturbance agent (Flannigan et al., 2001; Bergeron et al., 2011). These studies rely on fossil charcoal deposited in lake sediments and peat as a paleoecological proxy of fire events (Whitlock and Larsen, 2002). However, due to the lack of effective proxies for reconstructing insect-related disturbance, the frequency, intensity and impacts of past insect outbreaks on the forest landscape have been neglected or over-simplified. Nonetheless, insect outbreaks are one of the most influential factors that shape forest diversity (McCullough et al., 1998). Spruce budworm [Choristoneura fumiferana (Clemens)] (SBW) is the most important defoliator of conifer trees in the North American boreal forest. At the epidemic stage, massive populations of larvae cause widespread damage to tree foliage. The larvae then undergo a metamorphosis to produce enormous flights of moth (Boulanger et al., 2017; Figure 1a). In the province of Quebec (Canada), the forest surface affected by this species of 
Lepidoptera over the last century is twice the size of the state of California (Morin et al., 2009). SBW epidemics not only have major ecological impacts but also produce important economic consequences due to the loss of forest productivity (Shorohova et al., 2011). Despite the scale and significance of this natural disturbance agent, there is limited knowledge regarding the frequency and severity of SBW outbreaks at a pluri-millennial scale as well as how these outbreaks are related to climate. Given that variations of temperature and precipitation affect organisms' survival, reproduction cycles and spatial dispersion (Dale et al., 2001), it is critical to understand the links between past SBW outbreaks and climate so as to understand the potential of SBW outbreaks under future climate change scenarios (Volney and Fleming, 2000; Klapwijk et al., 2013).

Previous studies on long-term SBW dynamics focused on indirect measurements of the insect's activity over the last few centuries (e.g., dendrochronology, aerial surveys, inventories, etc.) (Swetnam and Lynch, 1993; Gray et al., 2000; Boulanger and Arseneault, 2004; Bouchard et al., 2006; Bouchard and Auger, 2014). Lake sediments can be considered as natural "hard drives" recording the environmental conditions and events that affect the surrounding landscape over time (Dodd and Stanton, 1990). The stored information in this ecological hard drive must be interpreted using proxy indicators found within the sediment record (Bigler and Hall, 2002; Mauquoy and Van Geel, 2007). An efficient paleoindicator must be abundant, easy to identify and remain well-preserved over a long period of time. Until recently, the reconstruction of forest insect dynamics was limited to the analysis of fossil insect feces and cephalic head capsules recovered from peat (Simard et al., 2006); these proxies do not entirely meet the required criteria. For example, feces are essentially constituted of organic matter and as such are easily degradable, while cephalic head capsules are difficult to identify and are produced in very small quantities.

Most SBW studies have focused on the larval stages for which fossilized remains are not preserved in lake sediments. However, working in the Lake Saint-Jean region of Quebec during a recent (2014) SBW infestation, we observed large quantities of adult moth wing scales in the water column, which eventually settle onto the lake bottom. This lead us to believe that due to the chitinous composition of these body parts, the adult SBW stages could be preserved in the sediment record of lakes, and thus serve as a potential paleoindicator of outbreaks. Etymologically, Lepidoptera means "scaled wings", although scales not only cover the wings, but also the thorax, abdomen and genital apparatus of moths. Our observations determined that significant amounts of Lepidoptera scales float on the lake surface to form "scale belts" (Figures 1b,c; Ghiradella, 1998) produced as individual die and the membranes and sockets dry, releasing the scales. In addition to the thousands of scales present on each wing of each individual moth, certain scale shapes can be associated to specific taxa allowing for specific taxonomic identification of moth species. As such, these scales seem to match a priori all criteria for being an effective paleoindicator, although previous studies had never reported them from the sediment record.
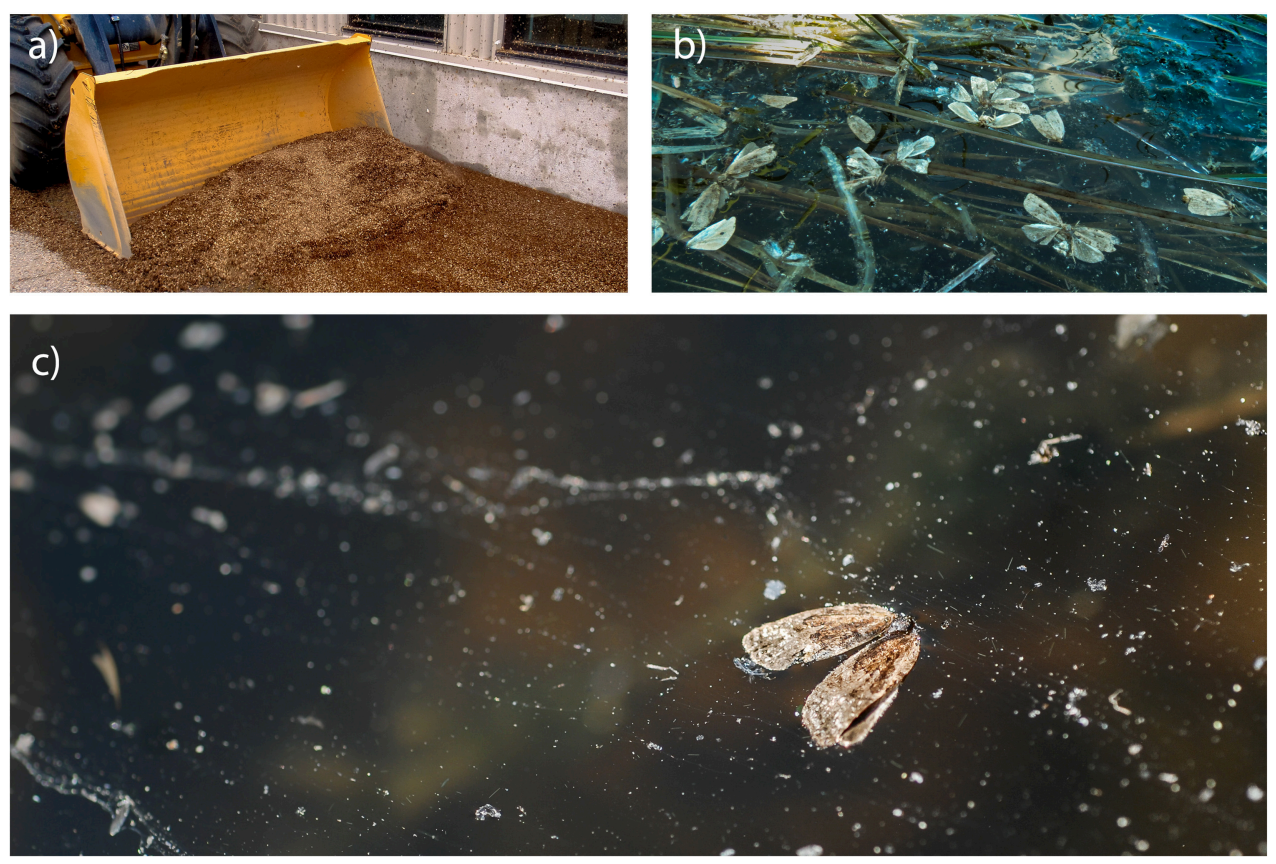

FIGURE 1 | Images from spruce budworm (Choristoneura fumiferana - SBW) outbreaks. (a) Millions of dead moths in a forest camp after a massive flight of SBW in 2014. (b) Dead moths floating on the surface of a boreal lake north of Lake Saint-Jean, Quebec, in 2017. (c) Scale belts and other components separated from moths lying on the water surface. 
Fire reconstruction uses charcoal fragments extracted from sediment by sieving methods, a technique not suitable for recovering lepidopteran scales as the mesh sizes used for charcoal are much too large. Pollen grains, studied by palynologists, are similar in size to scales, but the extraction of pollen from sediment requires the use of destructive acids that dissolve the more delicate lepidopteran remains. According to Kristensen and Simonsen (2003), the reticulated structure of lepidopteran scales renders them poorly wettable and improves their floatability. We took advantage of these characteristics to propose an efficient and relatively simple extraction protocol (Navarro et al., 2017). The procedure involves the sieving of sediment with an appropriate

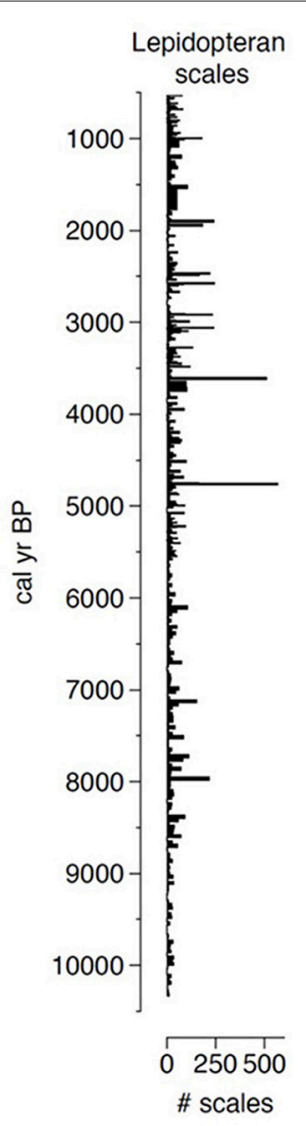

FIGURE 2 | Raw number of lepidopteran scales extracted for the last 10,000 years from a sediment core recovered from Lake Flévy, Quebec. mesh size followed by multiple centrifugations of the rinsed sediment to precipitate the higher density organic matter and to cause lower density particles, such as some pollen and most of the scales, to float to the surface. These insect remains then form a concentrated subsample that can then be mounted onto microscope slides for analysis.

This novel approach allowed us to extract lepidopteran scales from nearly every centimeter of a $500-\mathrm{cm}$-long sediment core representing 10,000 years of deposition (Figure 2). Before attributing any high abundance of fossil scales to past SBW activity, we needed to identify the extracted scales and link them to outbreak species. Given that the shape of wing scales varies between species of Lepidoptera (Anken, 1996) and that this was relatively easy to measure, we evaluated the shape of thousands of scales from the main epidemic species found in Canada. These measurements lead to the development of species-specific morphotypes that we could use as an identification support tool (Figure 3). It must be noted that with the scales being very thin and delicate, a significant portion of the extracted scales were broken, folded or covered by other material resulting in a relatively low rate of scale identification. Nonetheless, we could still confirm that peaks of identified fossil scales corresponded to periods of insect outbreak. Thus, considering the wide range of SBW outbreaks on affected areas, and as it is the most damaging defoliator, we confirm that lepidopteran scales are an excellent indicator of SBW abundance.

Analysis of the long-term history of insect outbreaks opens the door to an improved understanding of: (1) the interactions between different disturbances at the Holocene scale, (2) the role of insect outbreaks on landscape dynamics and (3) the relationship between climate and insect outbreaks at short-term and pluri-millennial scales. Use of fossil Lepidoptera wing scales also offers numerous potential insights into natural disturbance controls on forest structure with implications for biodiversity conservation and forest management. Insect outbreaks are cyclic phenomena based on the regulation of population density (Royama, 1984). Scales provide a direct measurement of the abundance of Lepidoptera over time, allowing insight into the impact of insect outbreaks on the forest structure and composition in relation to outbreak severity and frequency. Reconstruction of outbreaks would also provide a longer-term vision of insect dynamics and interactions with other natural factors over time (e.g., wildfire versus insect outbreaks versus climate). Furthermore, sustainable forestry management aims to ensure that harvest methods simulate patterns of natural

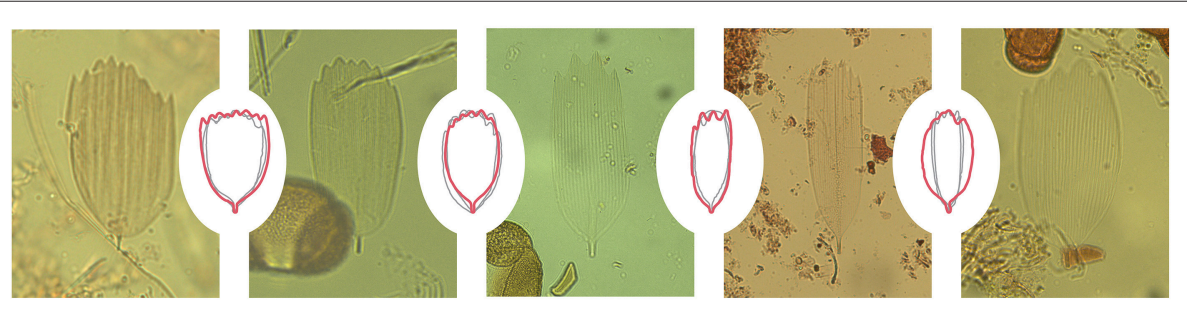

FIGURE 3 | Examples of well-preserved scales extracted from a lake sediment core showing the correspondence with spruce budworm (SBW) morphotypes generated from the shape measurements of thousands of SBW specimen scales. 
disturbance and thus minimize differences between managed and natural forests (Kuuluvainen, 2002; Gauthier et al., 2009; Montoro Girona et al., 2016). Understanding the pattern of insect outbreaks will permit mirroring silvicultural practices to the natural severity and frequency of insect outbreaks (Hof et al., 2017). Finally, in the context of climate change that will likely impact the occurrence of insect outbreaks, a longer record of outbreak cycles and consequences would improve forecasts of future ecological scenarios and potential change (Intergovernmental Panel on Climate Change, 2014).

Although we have focused primarily on SBW outbreaks, lepidopteran scales show great potential for other purposes. With more than 160,000 described species, Lepidoptera (moths and butterflies) is the second most diverse faunal order, with the total number of probable species estimated at almost half a million (Kristensen et al., 2007). Lepidoptera are considered to be an effective "umbrella group" for biodiversity conservation, and, globally, there is a high extinction risk for these species (New, 1997; Thomas et al., 2004). Analyses of wing scales could improve our knowledge of the abundance and distribution (e.g., migration, range shifts) of these species, and provide an understanding of how moths reacted to past environmental change, to better discern their future vulnerability to extinction. The use of lepidopteran scales from the past will provide insight into present-day ecosystems and produce a more accurate projection of insect outbreaks that will occur in the future.

\section{REFERENCES}

Anken, R. H. (1996). On the taxonomic value of the morphology of wing scales in some Heliconiinae (Lepidoptera, Nymphalidae). Iheringia Sér. Zool. 81, 139-144.

Bergeron, Y., Cyr, D., Girardin, M. P., and Carcaillet, C. (2011). Will climate change drive 21 st century burn rates in Canadian boreal forest outside of its natural variability: collating global climate model experiments with sedimentary charcoal data. Int. J. Wildland Fire 19, 1127-1139. doi: 10.1071/WF09092

Bigler, C., and Hall, R. I. (2002). Diatoms as indicators of climatic and limnological change in Swedish Lapland: a 100-lake calibration set and its validation for paleoecological reconstructions. J. Paleolimnol. 27, 97-115. doi: 10.1023/A:1013562325326

Bouchard, M., and Auger, I. (2014). Influence of environmental factors and spatiotemporal covariates during the initial development of a spruce budworm outbreak. Landsc. Ecol. 29, 111-126. doi: 10.1007/s10980-013-9966-x

Bouchard, M., Kneeshaw, D., and Bergeron, Y. (2006). Forest dynamics after successive spruce budworm outbreaks in mixedwood forests. Ecology 87, 2319-2329. doi: 10.1890/0012-9658(2006)87[2319:FDASSB]2.0.CO;2

Boulanger, Y., and Arseneault, D. (2004). Spruce budworm outbreaks in eastern Quebec over the last 450 years. Can. J. For. Res. 34, 1035-1043. doi: 10.1139/x03-269

Boulanger, Y., Fabry, F., Kilambi, A., Pureswaran, D. S., Sturtevant, B. R., and SaintAmant, R. (2017). The use of weather surveillance radar and high-resolution three dimensional weather data to monitor a spruce budworm mass exodus flight. Agric. For. Meteorol. 234, 127-135. doi: 10.1016/j.agrformet.2016.12.018

Dale, V. H., Joyce, L. A., Mcnulty, S., Neilson, R. P., Ayres, M. P., Flannigan, M. D., et al. (2001). Climate change and forest disturbances. Bioscience 51, 723-734. doi: 10.1641/0006-3568(2001)051[0723:CCAFD]2.0.CO;2

Dodd, J. R., and Stanton, R. J. (1990). Paleoecology: Concepts and Applications. New York, NY: John Wiley \& Sons.

Flannigan, M., Campbell, I., Wotton, M., Carcaillet, C., Richard, P., and Bergeron, Y. (2001). Future fire in Canada's boreal forest: paleoecology results and general

\section{AUTHOR CONTRIBUTIONS}

MM conceptualized the paper; LN and HM designed the paleoecological study and contributed to its realization; LN carried out lab work and paleoecological analyses; MM wrote the first draft of the manuscript; LN contributed to the writing of the manuscript; HM supervised the investigation and provided substantial input to the interpretation of results; $\mathrm{HM}$ also secured funding for the project. All authors contributed to the revision of the manuscript, read and approved the submitted version.

\section{FUNDING}

Funding was provided by the Natural Sciences and Engineering Research Council (NSERC) of Canada, the Canada Research Industrial Chairs Program, Canada Foundation for Innovation and the Fonds de Recherche de Québec-Nature et Technologies obtained by the last author.

\section{ACKNOWLEDGMENTS}

We thank E. Tremblay for field assistance, A.E. Harvey for lab assistance, Y. Boulanger for technical advice, G. Grosbois and V. Bergeron for logistical help.

circulation model-regional climate model simulations. Can. J. For. Res. 31, 854-864. doi: 10.1139/x01-010

Gauthier, S. V. M. A., Leduc, A., De Granpré, L., Kneeshaw, D., Morin, H., Drapeau, P., and Bergeron, Y. (2009). Ecosystem Management in the Boreal Forest. Quebec, QC: Presses de l'Université de Québec.

Ghiradella, H. (1998). "Hairs, bristles, and scales," in Microscopic Anatomy of Invertebrates, eds F. W. Harrison (New York, NY: Wiley-Liss), 257-287.

Gray, D. R., Régnière, J., and Boulet, B. (2000). Analysis and use of historical patterns of spruce budworm defoliation to forecast outbreak patterns in Quebec. For. Ecol. Manag. 127, 217-231. doi: 10.1016/S0378-1127(99)00134-6

Hof, A. R., Dymond, C. C., and Mladenoff, D. J. (2017). Climate change mitigation through adaptation: the effectiveness of forest diversification by novel tree planting regimes. Ecosphere 8:e01981. doi: 10.1002/ecs2.1981

Intergovernmental Panel on Climate Change. (2014). Climate Change 2014Impacts, Adaptation and Vulnerability: Regional Aspects. Cambridge University Press.

Klapwijk, M. J., Csóka, G., Hirka, A., and Björkman, C. (2013). Forest insects and climate change: long-term trends in herbivore damage. Ecol. Evol. 3, 4183-4196. doi: 10.1002/ece3.717

Kristensen, N. P., Scoble, M. J., and Karsholt, O. (2007). Lepidoptera phylogeny and systematics: the state of inventorying moth and butterfly diversity. Zootaxa 1668:e747.

Kristensen, N. P., and Simonsen, T. J. (2003). 2. 'Hairs' and scales. Handbuch Der Zoologie/Handbook of Zoology 4:9.

Kuuluvainen, T. (2002). Natural variability of forests as a reference for restoring and managing biological diversity in boreal Fennoscandia. Silva Fennica 36, 97-125. doi: 10.14214/sf.552

Mauquoy, D., and Van Geel, B. (2007). "Plant macrofossil methods and studies: mire and peat macros," in Encyclopedia of Quaternary Science, ed A. E. Scott (Amsterdam: Elsevier Science), 2315-2336.

McCullough, D. G., Werner, R. A., and Neumann, D. (1998). Fire and insects in northern and boreal forest ecosystems of North America. Annu. Rev. Entomol. 43, 107-127. doi: 10.1146/annurev.ento.43.1.107 
Messier, C., Puettmann, K. J., and Coates, K. D. (2013). Managing Forests as Complex Adaptive Systems: Building Resilience to the Challenge of Global Change. New York, NY: Routledge.

Montoro Girona, M., Morin, H., Lussier, J.-M., and Walsh, D. (2016). Radial growth response of black spruce stands ten years after experimental shelterwoods and seed-tree cuttings in boreal forest. Forests 7:240. doi: 10.3390/f7100240

Montoro Girona, M., Rossi, S., Lussier, J.-M., Walsh, D., and Morin, H. (2017). Understanding tree growth responses after partial cuttings: a new approach. PLOS ONE 12:e0172653. doi: 10.1371/journal.pone.0172653

Morin, H., Laprise, D., Simard, A.-A., and Amouch, S. (2009). "Spruce budworm outbreak regimes in eastern North America," Ecosystem Management in the Boreal Forest, eds S. Gauthier, M.-A. Vaillancourt, A. Leduc, L. De Grandpré, D. Kneeshaw, H. Morin, P. Drapeau, and Y. Bergeron (Québec, QC: Presse de l'Université du Québec), 155-182.

Navarro, L., Harvey, A.-É., and Morin, H. (2017). Lepidoptera wing scales: a new paleoecological indicator for reconstructing spruce budworm abundance. Can. J. For. Res. 1-7. doi: 10.1139/cifr-2017-0009

New, T. (1997). Are Lepidoptera an effective 'umbrella group' for biodiversity conservation? J. Insect Conserv. 1, 5-12. doi: 10.1023/A:1018433406701

Royama, T.-O. (1984). Population dynamics of the spruce budworm Choristoneura fumiferana. Ecol. Monogr. 54, 429-462. doi: 10.2307/ 1942595

Shorohova, E., Kneeshaw, D., Kuuluvainen, T., and Gauthier, S. (2011). Variability and dynamics of old-growth forests in the circumbolear zone: implications for conservation, restoration and management. Silva Fenica 45, 785-806. doi: $10.14214 /$ sf.72
Simard, I., Morin, H., and Lavoie, C. (2006). A millennial-scale reconstruction of spruce budworm abundance in Saguenay, Quebec, Canada. Holocene 16, 31-37. doi: 10.1191/0959683606hl904rp

Swetnam, T. W., and Lynch, A. M. (1993). Multicentury, regional-scale patterns of western spruce budworm outbreaks. Ecol. Monogr. 63, 399-424. doi: $10.2307 / 2937153$

Thomas, C. D., Cameron, A., Green, R. E., Bakkenes, M., Beaumont, L. J., Collingham, Y. C., et al. (2004). Extinction risk from climate change. Nature 427, 145-148. doi: 10.1038/nature02121

Volney, W. J. A., and Fleming, R. A. (2000). Climate change and impacts of boreal forest insects. Agric. Ecosyst. Environ. 82, 283-294. doi: $10.1016 / 50167-8809(00) 00232-2$

Whitlock, C., and Larsen, C. (2002). "Charcoal as a fire proxy, in Tracking Environmental Change Using Lake Sediments, eds J. P. Smol, H. J. B. Birks, and W. M. Last (Dordrecht: Kluwer Academic), 75-97.

Conflict of Interest Statement: The authors declare that the research was conducted in the absence of any commercial or financial relationships that could be construed as a potential conflict of interest.

Copyright (๑) 2018 Montoro Girona, Navarro and Morin. This is an open-access article distributed under the terms of the Creative Commons Attribution License (CC $B Y)$. The use, distribution or reproduction in other forums is permitted, provided the original author(s) and the copyright owner are credited and that the original publication in this journal is cited, in accordance with accepted academic practice. No use, distribution or reproduction is permitted which does not comply with these terms. 